\title{
Pregnancy, obstetrics and the moral status of the fetus
}

\author{
Raanan Gillon Imperial College of Science and Technology and King's College, London University
}

In this issue Dr Garland Anderson, Chief of the 'Maternal-Fetal Medicine' Department at the University of Tennessee in Memphis USA, and Dr Carson Strong, medical ethicist in the same institution, consider the ethical issues confronting mothers and obstetricians in the very specific and fairly rare circumstances of premature labour when the fetus is in the 'breech' (legs first) position, and the decision has to be made whether or not to carry out the operation of caesarean section. Their paper is an excellent example of the benefits that co-operation between physician and philosopher can confer, with its careful analysis of the empirical data combined with philosophical analysis of the issues involved.

The central problem they consider - how to try to weigh up the interests of the fetus/child-to-be with those of the pregnant woman of cuurse transcends their carefully circumscribed circumstances of premature breech labour and affects a whole range of obstetric and gynaecological situations including (at least) questions of postcoital and possibly progesterone-only contraception, abortion, therapy for the pregnant woman during pregnancy, and, increasingly, therapy for the fetus during pregnancy.

One of the central concerns in moral argument about this cluster of issues is the moral status of the embryo/ fetus and Anderson and Strong devote a considerable part of their paper to defending the thesis that fetuses of more than 1000 grams 'should be regarded as having the full status of persons'. Suppose, however, that such a thesis were rejected, as it is by many, and fetuses were not to be regarded as having yet attained the full status of persons, what difference would it make to the decision-making considered by Anderson and Strong? Except where the intention was to kill the fetus circumstances with which they do not concern themselves - it seems that the answer is: very little difference. For regardless of the actual moral status of the fetus, if it is as matter of fact likely to become a person, then it ought to be treated with the same moral respect as persons are treated, at least with regard to avoiding doing to it anything that will impair it when it becomes a person.

That possibly startling claim clearly requires justification. It is based on the fairly uncontentious assumption that because all human people are the same biological spatio-temporal continuants - the same $\stackrel{\oplus}{-}$ human lives - that they were as embryos and as fetuses, $\stackrel{\oplus}{-}$ much that is done to them from conception onwards $\omega$ can affect them as people. This in no way entails that음 they were people at or around conception onwards but $\rightarrow$ it does justify the (prima facie) moral claim that those 3 entities that are to become people must not be treated in a way that will harm the people they are to become. For if I have a (prima facie) moral obligation not to $\overrightarrow{0}$ harm person $\mathrm{y}$ and doing a to $\mathrm{x}$ will harm $\mathrm{y}$ then I have ${ }^{\circ}$ a (prima facie) moral obligation not to do a to $x$. Thus if, for example, an embryo $\mathrm{x}$ is to develop into a person $\mathrm{y}$, and giving thalidomide to the pregnant woman who is gestating $\mathbf{x}$ is likely to inflict the harm on $\mathbf{y}$ of having physical deformities, then there is a (prima facie) moral $\stackrel{\varnothing}{\varnothing}$ obligation to avoid giving thalidomide to the pregnant $\stackrel{2}{\Rightarrow}$ woman and thus to $\mathrm{x}$, and this obligation is quite $\frac{0}{3}$ independent of the moral status of $x$.

Similarly if delivering a 1000-2000 gram breech fetus $\mathbf{x}^{1}$ by vaginal delivery is substantially more likely to cause significant harm to the person $y^{1}$ that $x^{1}$ will $\bar{\Phi}_{\bar{\Phi}}$ become than if $\mathbf{x}^{1}$ is delivered by caesarean section, then $\overline{-}$ the prima facie moral obligation not to harm persons 3 . entails a prima facie obligation to deliver by caesarean ${ }_{0}^{\circ}$ section rather than vaginally, whether or not the fetus $x^{i} \gtreqless$ is already the person $y^{1}$. (Prima facie is an importanto qualification here because as Anderson and Strong point out the operation carries a definite increased risk을 of death and morbidity for the woman and it is for her $\mathrm{N}$. to decide whether or not to accept that risk to herself in. the interests of her baby.)

It is crucial to be clear however that this argument in N no way entails that all embryos and fetuses (whatever $\sigma$ their weight or viability) are to be accorded the care and protection that we are obliged to accord to each other, $\frac{\bar{\Phi}}{\overparen{D}}$ for it is only those embryos and fetuses that are to develop into people to whom it applies. Thus the argument offered above is entirely consistent with claims that it is justifiable to end the existence of $\vec{\odot}$ embryos and fetuses when there are good reasons for $\overrightarrow{\mathbb{D}}$ doing so. Why? Because if the premises are accepted $\frac{}{\sigma}$ (a) that embryos and fetuses are not people and (b) that our prima facie obligation not to kill living entities foro the benefit of people refers only to those living entities that are people, it is prima facie justifiable to kilko embryos and fetuses for the benefit of people, even? 
though it is also prima facie not justifiable to do anything to embryos which will cause harm to the people they will become if they are not killed. Thus if the position is accepted that embryos and fetuses are not persons it may, prima facie, be justifiable to kill them in the interests of others; but if they are to be allowed to continue their development into people then, prima facie, it is not justifiable to do things to those embryos or fetuses that will cause harm to the people they are to become.

One important counter-argument that must be considered is the claim that if it is accepted, as above, that human people are spatio-temporally continuous with the embryos and fetuses they once were - that they are the same biological entities, indeed the same human beings - then as Dr Iglesias put it in this journal, ' . . to be a human being is to be a person. There are no stages in our existence at which this identity does not hold' (1).

The argument, a common one in Roman Catholic theology and also in common sense argumentation about abortion, is plausible when applied retrospectively to human persons. If I am the same thing as the embryo I once was then if I am a person the embryo must be a person - for when $\mathrm{x}$ is the same as $\mathrm{y}$ then whatever is true of $x$ must be true of $y$ (Leibniz's Law of Identity).

The obvious objections to this line of argument do not work. Thus to say it's obviously false because the fetus that I was did not have grey hair and I do is only apparently problematic - as Wiggins elegantly shows (2) it is a question of tensed versus tenseless description. It is true of the fetus I once was that it will have grey hair even though also true that it does not as a fetus have grey hair. Similarly it is true of the fetus I once was that it will be the person I am - and thus in a sense the counterargument goes through, for in a tenseless way of speaking it is true of the fetus that I was that it is the person I have become. But, as with the grey hair, there is no reason in logic why it should therefore be true of the fetus that it was then a person.

As Wiggins equally elegantly shows, while some things are (present-tensedly) true of an entity at any time throughout its existence, other things are only (present-tensedly) true of it during part of its existence. Having grey hair is clearly a property of the latter sort - what Wiggins calls a 'phased sortal', in contrast to properties that a thing has throughout its existence which Wiggins calls substance sortals (or substance concepts). There is no reason in logic to deny the possibility that being a person may be only a temporal phase in the existence of some human lives and that conversely some human lives could be completed without ever becoming the lives of human persons notably the lives of embryos and fetuses that do not, for whatever reason, develop sufficiently to become persons.
If this sort of reasoning is accepted (and of course it needs far more thorough analysis and justification than is possible here and would be vigorously repudiated by, amongst others Roman Catholics), then it can be entirely consistent both to reject the claim that embryos and fetuses are persons, and to accept the claim that all human persons have been human embryos and fetuses. It can also be entirely consistent both to be prepared to kill embryos and fetuses in the sufficient interests of others (as for example with postcoital contraception, embryo research followed by destruction for the benefit of future patients and the destruction of fetuses - abortion - in the interests of the pregnant woman or other members of her family, as currently permitted under the British Abortion Act), and yet also to argue as above that for any embryo/fetus that is intended to be kept alive and allowed to develop normally and become a person nothing should be done to it that would harm the person it will become which would not be acceptable if done to a 'fully fledged' person.

Such a view is compatible with the position advocated by Anderson and Strong that in the case of sufficient probability of a sufficiently more successful outcome for the fetus (and thus for the person it is or, under the view outlined above, will become) it is justifiable to offer to the pregnant woman the higher personal risk of a caesarean section in the interests of her baby-to-be. It is also compatible with their view that in the circumstances they discuss the fetus should be treated as having the moral standing of a person not because it is a person, but because it is intended, and very likely, that it will become one.

Unlike the view offered by Anderson and Strong, however, the position outlined above would not require all fetuses of more than 1000 grams to be treated as persons. It would thus permit destruction of the fetus - of whatever weight and stage of development - in cases where not to destroy the fetus would seriously threaten the pregnant woman's life. This is permitted in current British law under the terms of the Infant Life (Preservation) Act, seems to accord with widespread (though by no means universal) moral intuitions that where the life of a pregnant woman is threatened by continuation of a pregnancy, abortion is justified, but would surely not be permitted if Anderson and Strong's recommendation were generally accepted that all 'fetuses in the weight range in question [1000 grams and over] should be regarded as having the full status of persons'.

\section{References}

(1) Iglesias T. In vitro fertilisation: the major issues. Fournal of medical ethics 1984; 1: 32-37.

(2) Wiggins D. Sameness and substance. Oxford: Blackwell, 1980. 